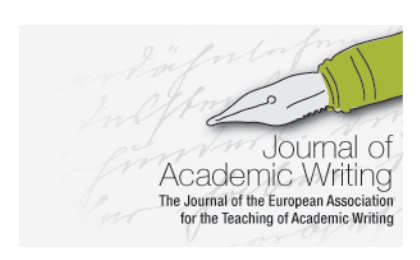

Journal of Academic Writing

Vol. 5 No 2 Summer 2015, pages 43-47

http://dx.doi.org/10.18552/joaw.v5i2.228

\title{
Review of $A$ Language as Social Semiotic-Based Approach to Teaching and Learning in Higher Education
}

\author{
Sally Mitchell \\ Thinking Writing, Queen Mary University of London, UK
}

\begin{abstract}
Coffin, Caroline and Donohue, Jim (2014) A Language as Social Semiotic-Based Approach to Teaching and Learning in Higher Education. Wiley-Blackwell, pp. 212, £28.50, ISBN 9781118923825
\end{abstract}

In her recent article 'Re-integrating Academic Development and Academic Language and Learning: a Call to Reason' (2014), Alisa Percy describes the historically separate trajectories in universities (in Australia but also more widely) of professional expertise in academic (educational) development and academic language and learning. She argues that this separation (in which, broadly, the former is staff-facing whilst the latter is student-facing) is unhelpful and calls for a reintegration of language and literacy expertise with academic development work in order to 'promote the development of students' language and learning simultaneously' (2014:1203). Percy's analysis and her conclusions are convincing to me. If I'm asked at a party what my job is (groan), I'm never quite sure which professional title to adopt - educational developer, writing developer, learning developer, academic developer - and, similarly, as its chronic institutional grumblings attest, the university in which I work is also never quite definitively cured of its anxieties about where the work I do should belong (historically over here, logically perhaps over there?). Conveniently sheltering under the nonpindownable, un-institutional, and non-generic name, 'Thinking Writing', the team in which I work has always taken the view that language and learning - and knowing and being and doing - are intimately connected, and that attention to language (writing specifically) is - at least in principle - as much the responsibility of disciplinary academics as is the teaching and learning of disciplinary content; the two, that is, can't really be separated.

This is not an easy principle to put into practice, however. The academic/writing developer becomes engaged in helping academics to help students take on the ways of thinking, being, doing, knowing that are characteristic of the discipline, or rather (as this is often not precisely the same thing), required for success in specialised degree programmes. Practically this work may include discussion of what tasks to set, how to develop teaching around these, how to assess the tasks, how, and on what, to give meaningful and effective feedback. But knowing how, in both practical and conceptual terms, to focus in with academics on what we claim to be key - the ways that students are using written language to show, or to fail to show, their disciplinary learning - is something we are not always fully equipped or confident to do.

It's pretty widely acknowledged in our field that discussions with academic teachers around language and writing can easily become focussed around student error and deficiencies in 'grammar' - a illdefined notion but one that academics are mostly clear they did not come into the profession to teach and wouldn't know how to. In these discussions it's not easy to place a dividing line between disciplinary language (for which, my argument goes, the academic has responsibility since language and content are inextricably intertwined in making disciplinary meaning) and basic language or perhaps, grammar. In practice - that is, largely, in the act of reading and marking texts - the academic is faced with both. 
One of my aims, I guess, is to make this practice interesting to academics. In the past I have very occasionally used the following passage with academic colleagues. It's I. A. Richards (1929) talking about reading poems with undergraduate students:

Between the bare apprehension of the literal sense of a passage and the full comprehension of all its meaning in every kind, a number of halfway houses intervene. To ascertain, even roughly, where failure has occurred, is in many cases beyond our power. [...] Inability to construe may have countless causes. Distractions, preconceptions, inhibitions of all kinds have their part, and putting our finger on the obstructing item is always largely guesswork. The assumption, however, that stupidity is not a simple quality, such as weight or impenetrability were once thought to be, but an effect of complex inhibitions is a long stride in a hopeful direction. The most leaden-witted blockhead thereby becomes an object of interest. (43)

My intention is to prick my subject-based colleagues' intellectual curiosity (and perhaps consciences) about the students on whose writing they form judgements. There is something haughty, and perhaps downright rude, about Richards' implicit belief here that as the connoisseur he holds full comprehension of all the meanings of every kind - but this is why I like the quote. It simultaneously questions the authority of the teacher whilst exposing the qualities that may make him, if not exactly student-centred in his thinking, then at least student-oriented, open and enquiring rather than dismissive.

Why then might I think Coffin and Donohue's book, A Language as Social Semiotic-Based Approach to Teaching and Learning in Higher Education, is worth recommending? What does it offer me and, directly or indirectly, the academics I work with? How might it help me tackle the issue of students' language development in ways that retain the interconnectedness with disciplinary learning, and thus strengthen in practical and conceptual ways my espoused position that they are connected and therefore part of mainstream teaching development? How might it help me engage my academic colleagues?

The book is framed front and back by discussions of the higher education context; it lays out first in comprehensive theoretical terms and then through application of the theory in three actual teaching and learning settings what the authors mean by advocating a 'Language as Social Semiotic Approach' (LASS). The basic theory of language is Systemic Functional Linguistics (SFL), and there are explanations of field, tenor, mode, etc. as well as extended discussions of genres. Getting to grips with SFL is a bit like peeling an onion - possibly in reverse; there's always another layer of analytical tools (Theme, Hyper-theme, Macro-theme... Participants, Processes, Circumstances...) to be exposed or applied. Happily, the reader gets to develop some familiarity with these tools by seeing them at work through the book's absorbing case studies which contextualise 'texts' with strong evocations of people and situation.

What's most interesting about the Language as Social Semiotic Approach is the way it knits together the analytical with the pedagogical. So, overlaying the set of tools for building understanding of texts are concepts that provide the means for linking texts to people and to contexts (and vice versa) and therefore for building ways of working together (teachers with students, writing developers with subject lecturers) to create change (better teaching, better learning). Key concepts here are 'semantic orientation' (from Hasan, 2009) which refers to the dispositions people bring to meaning making and language use from their previous experience and, 'meta-semiotic mediation' which refers to making 'semiotic mediation' - i.e. what is going on in a piece of language in use - visible or explicit.

My favourite part of the book is the case study of Zuna, a Health and Social Care student whose essay text is explored through a detailed dialogue with Donohue (Chapter 5). The framing of this case study will be familiar to readers: the authors got to work with Zuna when they were asked into the HSC course to develop materials that would fix the students' writing at the level of the sentence. As the dialogue and analysis unfold, what is revealed is how Zuna's 'semantic orientation' to the content she had to work with guided the ways she expressed and ordered her essay. We begin to see clearly 
that her low-scoring text is not (to borrow I. A. Richards' terms) 'a simple quality' but 'an effect of complex inhibitions' (Richards 1929: 43):

[...] ambiguities in Zuna's text could be traced back to: the meanings she extracted from her course reading material; her overall predisposition towards description, recount, and explanation rather than discussion; and an unfamiliarity with configuring the meanings in all these genres, especially with using the text-forming devices that underpin the genres (such as thematic development for foregrounding and backgrounding information, and evaluative language for creating linkages across text) and the phases of naming and defining concepts, relating concepts to one another, and framing illustrative case study material (Coffin and Donohue 2014: 182).

Zuna's 'overall predisposition toward description, recount and explanation' is an epistemological stance that Coffin and Donohue describe as 'categorical' rather than 'perspectival'. It then becomes fascinating to see how inserting a perspectival framing paragraph into Zuna's text dramatically shifts its orientation towards argument and evaluation, and in effect 'fixes' it. What's fixed, though, ain't grammar and it ain't the sentence...

What I like in Coffin and Donahue's analysis and intervention is the strong recognition of the student, and the strong motivation to understand, account for and so value her. There's a pervasive sense of careful listening and the book as a whole is characterised, despite its in-depth, theorised, sometimes painstaking analyses, by the individual voices both spoken and written of a diversity of students. Tyrrell and Everton (Chapter 4) are another pair. The detailed analysis of their Film Studies texts shows how they are 'building their representations of film differently', are 'analysing differently'; Tyrrell in a way that is recognised and valued by the discipline ('abstract Participants, metaphorical Processes, taxonomies, technical terms' (112), Everton in a way that is not, which is much more 'material' (112). Having established what makes the difference between the two students' written performances, the chapter moves on to describe a teaching sequence which helps the students to see the differences for themselves. The goal is to enable more students like Everton to write like Tyrrell, and there is evidence of success in achieving this.

Nonetheless, some might question this goal as overly normative and certainly it's possible to detect just the hint of a tension - the slippage in linguistics that Deborah Cameron (1995) talks about from description (neutral explication via the theoretical tools) into prescription (judgement and recommendation about more effective uses of language). I sensed this tension mainly in Chapter 6 , which looks at online discussion and where the analysis slides gently from accounting for what the empirical data presents in terms of genre theory, to suggesting what should happen in this genre if online forums are to be used as a way of developing the kinds of thinking that are valued in academic essays.

It is certainly the case that Coffin and Donohue take as a given starting point for their work the assumption that there are certain dominant characteristics of academic learning and writing - 'high levels of abstraction, judgment, evaluation and interpretation' (2) - and that socialisation into higher education will involve an orientation towards 'decontextualized meanings' (21). They also assume that higher education is, to a greater or lesser extent, different from earlier stages of education and other spheres of life and that people coming into higher education (students) are therefore likely to be entering a period of change which will have an impact on the way they think and use language. I guess this is what we mean by learning, but at least at the beginning of the book when they set out their stall, the way they demarcate the roles in higher education seems rather rigid - teacher as 'semiotic initiator' and student as 'semiotic responder'(27-8). 'Hold on!' I want to protest, 'You can't say that! At least not so acceptingly...'

But what's interesting is how such starting assumptions are played out in the case studies (what David Russell calls 'the crucible of practice' (2015: 181)). Because in case after case the student is the 'object of interest', and by page 151 of the book we get a reconsideration of the relationship posited at the beginning, and the learner is now in the semiotic initiator role with the teacher developing an understanding of the learner. 
And this is a radical rather than a conservative book - it puts students in all their diversity centrestage; it bridges the void left by the Enlightenment separation of language from knowledge and ideas, and counters the oversimplified but prevalent diagnosis of students' struggles with language as skillsdeficiency. It is also all about institutional change - the foregrounding of pedagogy that has the meaning-making functions of language at its heart - and in the final chapter it starts to build some, albeit tentative, evidence of where this change has happened.

So, how far has the book helped answer my questions? It has sharpened my insights with regard to the following: how meaning can be made differently in texts; why, and more precisely how, student texts may differ so much from each other; how contextualised and decontextualised meanings are made; how important the role played by semantic orientation (what I think of as epistemological stance) is in how a text turns out. It has also given me some theoretical, practical and strategic ideas for working in collaboration with discipline-based academics to make 'meta' what their expectations for language and writing are in their courses and programmes. For educational managers concerned with resource allocation (or for those seeking to persuade their managers) it makes a strong case for evidence gathering as the basis for proposing and designing changes to pedagogy and curricula. Such work is labour-intensive and there's no promise of a quick fix solution.

I suspect that what will enter my practice is 'LASS Lite' and I think this will be okay. This not a book, for example, I could directly share with my subject specialist colleagues. In terms of working with abstract conceptualisation, decontextualized knowledge, 'jargon' one might say, it certainly practices what it preaches. So for example, the noun phrase 'mediated text analysis' is used to capture what we might, on an everyday basis, think of as 'a conversation about a piece of writing'. And although I 'get' that 'mediated text analysis' lets me understand more about what's being meant by linking me into an abstract conceptual structure in which the players are semiotic initiators and semiotic responders etc., etc., my sense is that in working as a writing developer with my academic colleagues in the disciplines around the ideas from the book I would be doing a lot of translating; I couldn't, that is, expect them, at least in the shortish time we might be spending together, to take on the decontextualized meanings that the academic theory is painstakingly offering me. There are attempts by Coffin and Donohue to simplify but I'm not sure how far this works. Ironically, the proffered summary table of key points for teaching and learning (258) presents the knowledge as 'categorical' (becoming more like a text-book or pedagogical handbook that one can just pick up and learn from) and losing the perspectival drive of the preceding chapters. Just as students entering higher education can't shift their semantic orientation overnight, my sense is that academic staff would not be able to either.

Some caveats then about to whom the book will be immediately practically relevant - but for many working in language and particularly at the interface between language and academic development this should be an immensely insightful book and one that presents a significant but worthwhile challenge. Succeeding in the challenge would put language and literacy specialists at the heart of conversations about educational development in universities, working in partnership with disciplinebased academics to improve student learning. The agenda would not, in my view, be a necessarily normative one, but rather one led by enquiry, questioning assumptions about how students, teachers and disciplines are oriented towards knowledge and meaning and alert to how language choices carry and embody those orientations.

Coffin and Donohue's book provides us with a rich and serious resource for getting into this work; for responding to Alicia Percy's (2014) call for the integration of language and literacy specialisms into academic development expertise; and, if we are deft enough, for blasting away any ignorantly lingering views of our students as 'leaden-witted blockheads'.

\section{References}

Cameron, D. (1995) Verbal Hygiene. London: Routledge 
Hasan, R, (2009) The Ontogenesis of Decontextualized Language: Some Achievements of Classification and Framing. In J. Webster (Ed.) Semantic Variation: Meaning in Society and Sociolinguistics (403-432). London: Equinox

Percy, A. (2014) 'Re-integrating Academic Development and Academic Language and Learning: a Call to Reason', Higher Education Research and Development 33 (6): 1194-1207 http://dx.doi.org/10.1080/07294360.2014.911254

Richards, I. A. (1929) Practical Criticism: A study of literary judgment. London: Routledge and Kegan Paul

Russell, D. (2015) 'Thinking Critically and Negotiating Practices in the Disciplines. David Russell in Conversation with Sally Mitchell', in T. Lillis, K. Harrington, M. R. Lea and S. Mitchell (Eds) Working with Academic Literacies: Case Studies Towards Transformative Practice. Parlor Press: WAC Clearinghouse 